\title{
In Vivo Imaging of Monoaminergic Nerve Terminals in Normal and MPTP-Lesioned Primate Brain Using Positron Emission Tomography (PET) and $\left[{ }^{11} \mathrm{C}\right]$ Tetrabenazine
}

\author{
JEAN N. DASILVA, MICHAEL R. KILBOURN, AND EDWARD F. DOMINO \\ Division of Nuclear Medicine, Department of Internal Medicine (J.N.D., M.R.K.) and Department of \\ Pharmacology (E.F.D.), University of Michigan Medical Center, Ann Arbor, Michigan 48109
}

\section{KEY WORDS Dopamine, Parkinson's disease, Brain}

\begin{abstract}
The first successful in vivo imaging of monoamine vesicular transporters in the living primate brain is described, using $\left[{ }^{11} \mathrm{C}\right]$ tetrabenazine $\left(\left[{ }^{11} \mathrm{C}\right] \mathrm{TBZ}\right)$ and Positron Emission Tomography (PET). Radioligand uptake into brain is rapid, and at short time periods (10-30 minutes) the higher uptake and retention of the radiotracer in the more densely dopaminergic innervated striatum is clearly visualized. Specific binding in striatum can be entirely blocked with co-administration of a pharmacological dose $(1 \mathrm{mg} / \mathrm{kg}$ i.v.) of tetrabenazine. In a unilaterally MPTP-lesioned monkey, specific binding of radioligand was absent in the striatum on the lesioned side, with no effect on radiotracer distribution in the cortex, cerebellum or contralateral striatum. PET imaging with $\left[{ }^{11} \mathrm{C}\right] \mathrm{TBZ}$ provides a new approach to the in vivo study of monoaminergic neurons and their loss in neurodegenerative diseases. (c) 1993 Wiley-Liss, Inc.
\end{abstract}

\section{INTRODUCTION}

Considerable effort has been expended in the development of single photon emission computed tomography (SPECT) and positron emission tomography (PET) radioligands intended for in vivo quantification of monoaminergic nerve terminals and in particular for the development of potential neuronal markers for the dopaminergic system. Such efforts have resulted in the synthesis and in vivo evaluation of a number of new radiotracers, including $6-\left[{ }^{18} \mathrm{~F}\right]$ fluoroDOPA and 4- $\left[{ }^{18} \mathrm{~F}\right]$ fluoro-m-tyrosine, and the neuronal reuptake inhibitors $\left[{ }^{11} \mathrm{C}\right]$ nomifensine (Aquilonius et al., 1987), $\left[{ }^{11} \mathrm{C}\right]$ cocaine (Fowler et al., 1989), $\left[{ }^{11} \mathrm{C}\right]$ WIN 35,428 (also termed $\left[{ }^{11} \mathrm{C}\right] \mathrm{CFT}$ ) (Wong et al., 1992), $\left[{ }^{123} \mathrm{I}\right] \mathrm{RTI}-55$ (Shaya et al., 1992), [ ${ }^{123}$ I]CIT (Innis et al., 1991), $\left[{ }^{18} \mathrm{~F}\right]$ GBR 13119 (Kilbourn et al., 1989) and $\left[{ }^{18} \mathrm{~F}\right] \mathrm{GBR}$ 12909 (Koeppe et al., 1990). Although each radiotracer has unique characteristics of brain penetration, pharmacological specificity, and level of nonspecific uptake or binding, all have been successfully used to image dopaminergic neurons in primate or human brain.

As part of our studies with the aryldialk(en)ylpiperazines $\left[{ }^{18} \mathrm{~F}\right] \mathrm{GBR} 13119$ and $\left[{ }^{18} \mathrm{~F}\right] \mathrm{GBR} 12909$, we have demonstrated that the neuronal dopamine transporter (DAT) may be subject to regulation according to the chronic concentrations of endogenous dopamine (Kilbourn et al., 1992). This finding has been reported by others for the dopamine uptake system (Scheffel et al., 1991) and furthermore is common to the norepinephrine reuptake system (Lee et al., 1983). The $B_{\max }$ for DAT may also be altered by chronic treatments with drugs that bind at this site (Ikegami et al., 1990; Sharpe et al., 1991; Wiener et al., 1989). For the development of a true neuronal marker, the up- or downregulation of the numbers of reuptake sites per neurons might serve to, respectively, obscure neuronal degeneration or provide an unrealistically large estimate of neuron loss. For these reasons, we have continued our search for radiotracers for other presynaptic, high affinity binding sites that might serve as specific markers of neuronal numbers. We have recently described the synthesis and mouse brain distribution of $\left[{ }^{11} \mathrm{C}\right]$ tetrabenazine $\left(\left[{ }^{11} \mathrm{C}\right] \mathrm{TBZ}\right)$, a high affinity inhibitor of vesicular monoamine transport (DaSilva and Kilbourn, 1992). Although this transporter exhibits similar numbers and kinetics as the neuronal transporters, there is apparently no differentiation into systems specific for dopamine, serotonin, and norepinephrine (Slotkin and Bareis, 1980). Specific binding of $\left[{ }^{11} \mathrm{C}\right] \mathrm{TBZ}$ can thus be

Received October 30, 1992; accepted December 31, 1992.

Address reprint requests to Dr. Michael R. Kilbourn, 3480 Kresge III, University of Michigan, Ann Arbor, MI 48109-0552 
demonstrated in nearly all brain regions (striatum, cortex, hippocampus, hypothalamus, cerebellum), and the in vivo estimates of specific binding of $\left[{ }^{11} \mathrm{C}\right] \mathrm{TBZ}$ correlate well with both in vitro numbers of vesicular transporters (determined using $\left[{ }^{3} \mathrm{H}\right]$ dihydrotetrabenazine, $\left.\left[{ }^{3} \mathrm{H}\right] \mathrm{TBZOH}\right)$ or combined in vivo levels of monoamines (Scherman et al., 1986). $\left[{ }^{11} \mathrm{C}\right] \mathrm{TBZ}$ appears a suitable radioligand for the in vivo study of monoaminergic nerve loss, particularly in the striatum, which contains a high concentration of predominantly dopaminergic nerve terminals as compared to 5-HT or NE neurons. We describe here the first successful imaging of monoaminergic neurons in primate brain using a vesicular uptake inhibitor and PET and demonstrate that such binding sites are completely lost in the striatum on the affected side of a unilateral MPTP-lesioned primate brain.

\section{MATERIALS AND METHODS Radiotracer preparation}

High specific activity $\left[{ }^{11} \mathrm{C}\right]$ tetrabenazine was prepared by the $\left[{ }^{11} \mathrm{C}\right]$ methylation of 9-O-desmethylTBZ, as previously described (DaSilva et al., 1993). The radiotracer was purified using semipreparative silica gel chromatography and prepared for injection by evaporation of the HPLC solvent and dissolution in phosphate buffer. Radiochemical and chemical purity was then determined by reversed phase high pressure liquid chromatography. The specific activity of final product was $>1,000 \mathrm{Ci} / \mathrm{mmol}$ at time of injection, with a radiochemical purity $>95 \%$.

\section{Monkey PET studies}

PET imaging studies were done using two female pigtail monkeys (M. nemistrina, 6.6 and $4.6 \mathrm{~kg}$ ). One monkey had, $3^{1 / 2}$ years earlier, undergone a right unilateral carotid injection of MPTP ( $3 \mathrm{mg}$ total) using a modified method of Bankewicz et al. (1986). The animal developed persistent hemiparkinsonism on the contralateral side. Although used in pharmacological studies of dopamine agonists, the monkey had been drugfree for 1 month prior to the imaging study.

For each imaging session, the animals were anaesthetized with ketamine $(15 \mathrm{mg} / \mathrm{kg}$ i.m. and repeated as needed) and administered xylazine hydrochloride (2 $\mathrm{mg} / \mathrm{kg}$ i.m.). Studies were done using the TCC 4600 PET scanner (three-ring, five-slice tomograph) operating in the high resolution mode ( $12 \mathrm{~mm}$ FWHM). Cerebral blood flow studies using i.v. injections of $3-5 \mathrm{mCi}$ of ${ }^{15} \mathrm{O}$-labeled water were done prior to the $\left[{ }^{11} \mathrm{C}\right] \mathrm{TBZ}$ studies, to aid in positioning of the animals. The animals were then injected with $4.0-6.0 \mathrm{mCi}$ of $\left[{ }^{11} \mathrm{C}\right] \mathrm{TBZ}$ and sequentially imaged (30-second frames early, progressing to 10-minute frames at late times) for a total of 40 minutes. For the blocking study in the control animal, a no-carrier-added injection of $\left[{ }^{11} \mathrm{C}\right] \mathrm{TBZ}$ and imaging study was followed 1 hour later by injection of low specific activity $\left[{ }^{11} \mathrm{C}\right] \mathrm{TBZ}$ containing $1 \mathrm{mg} / \mathrm{kg}$ TBZ (Fluka Chem. Co.).

\section{RESULTS AND DISCUSSION}

After i.v. injection, $\left[{ }^{11} \mathrm{C}\right]$ tetrabenazine exhibits rapid brain uptake and clearance with a maximum brain concentration at 5 minutes. The slower release of the radioligand from the striatum, the site of the highest concentrations of vesicular transporters, results in clear visualization of this brain structure beginning at $\sim 10$ minutes after injection. The striatal to cerebellar ratio of radioactivity reaches a maximum value of about 2 at 20 minutes after injection; striatum to cortex values in monkeys ranged from 1.3 to 1.6 : a representative PET image is shown in Figure 1. Unlike radioligands specific for the dopaminergic system, $\left[{ }^{11} \mathrm{C}\right] \mathrm{TBZ}$ binds to vesicles of noradrenergic and serotonergic nerve terminals; as these are clearly present in the cerebellum and cortex, these tissues do not represent reference regions for only non-specific binding, and reporting of striatumto-cerebellum or striatum-to-cortex ratios are at best just approximations of the contrast between areas of high and low binding site densities. Evidence that the radioligand retention in the striatum was due to binding to specific vesicular transporters was provided by a blocking study, where a co-injection of $1 \mathrm{mg} / \mathrm{kg}$ unlabeled tetrabenazine completely abolished any regionselective accumulation of radioligand (data not shown). In previous studies in mice we have demonstrated that the in vivo binding of tetrabenazine is unaffected by neuronal dopamine uptake inhibitors or dopamine $D_{2}$ receptor antagonists, but is sensitive to competition with tetrabenazine, reserpine, and ketanserin, all known inhibitors of the vesicular transport of monoamines (DaSilva and Kilbourn, 1992).

In contrast to the symmetrical uptake of radioligand in brain of the control monkey, in the unilateral MPTPlesioned animal there was localization of the radiotracer in the striatum on only one side of the brain, corresponding to the unlesioned hemisphere (Fig. 1). Radiotracer uptake was unaffected in the cortex or unlesioned striatum (STR/CTX $=1.55$ at $30 \mathrm{~min}$ ), but was reduced to or below unity on the lesioned side (Fig. 2). This is consistent with the many reports of imaging of presynaptic dopaminergic functions in unilateral MPTP-lesioned animals using $\left[{ }^{18} \mathrm{~F}\right]$ fluoroDOPA or a variety of radiolabeled dopamine reuptake inhibitors (Leenders et al., 1988; Shaya et al., 1992).

Vesicular monoamine transporters are located exclusively in presynaptic monoaminergic terminals, and along with the neuronal transporters and the biosynthetic enzymes, tyrosine hydroxylase and tryptophan hydroxylase might serve as specific markers of presynaptic neuronal loss. Synaptic vesicular amine transporters (SVAT) are clearly distinct proteins that are quite different than the neuronal amine transporters; both the SVAT and DAT have been recently cloned and 


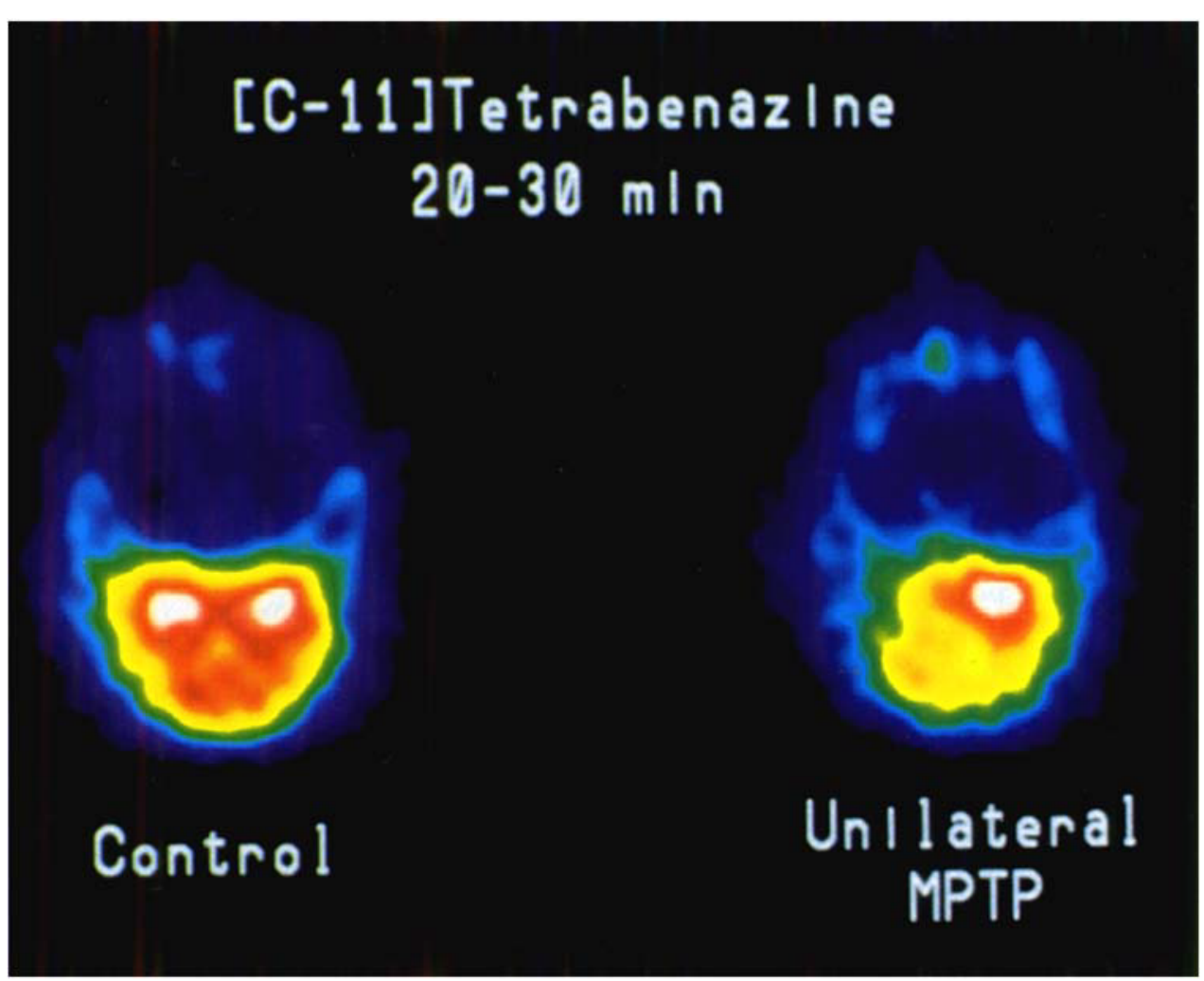

Fig. 1. PET images of $\left.{ }^{11} \mathrm{C}\right] \mathrm{TBZ}$ accumulation in striatum of normal (left) and unilateral MPTPlesioned (right) monkeys. Images represent accumulated counts for the period 20-30 minutes after i.v. injection of radiotracer.

sequenced (Giros et al., 1992; Liu et al., 1992), and although they both belong to the 12-transmembrane region transporter superfamily (Uhl, 1992), there is no sequence homology between them. Although it is recognized that the neuronal reuptake systems and the biosynthetic enzymes (Zigmond, 1985) are subject to regulation upon changes in physiological conditions, very little is known of the sensitivity of the vesicular transporter to regulation by endogenous dopamine levels. We are encouraged by preliminary experiments in mice where regulation of $\left[{ }^{11} \mathrm{C}\right] \mathrm{TBZ}$ binding could not be observed (DaSilva and Kilbourn, unpublished results) despite large alterations of brain dopamine levels induced by chronic pargyline treatment (Buu, 1989).

In this study, we have demonstrated that the vesicular transporters can be imaged in the living primate brain and that we can study the loss of such sites upon destruction of the dopaminergic terminal field in the striatum. Our results are consistent with the in vitro studies of 6-hydroxydopamine lesioned rats (Masuo et al., 1990) and of postmortem human brain tissue of Parkinson's disease patients (Scherman et al., 1989), which have shown a clear and dramatic loss of vesicular

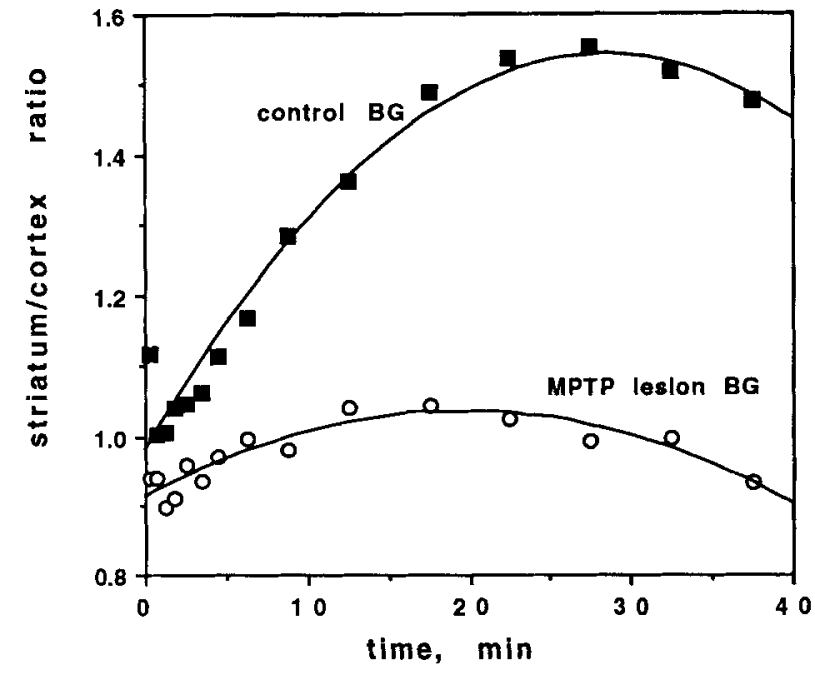

Fig. 2. Striatum/cortex ratios of radioactivity in PET scans of a unilateral MPTP-lesioned monkey. Regions of interest were placed over the right and left striatum, and cortex on both sides, and the time-dependent concentrations of radioactivity in those areas determined. Ratios represent the division of the striatal radioactivity by the average cortical radioactivity. 
binding sites (measured using $\left[{ }^{3} \mathrm{H}\right]$ dihydrotetrabenazine) consistent with the loss of nerve animals. The specific targeting of radiopharmaceuticals for the vesicular transporters is a new approach to in vivo imaging of the monoaminergic nervous system, but the concept is similar to the successful development in our laboratory (Jung et al., 1990; Kilbourn et al., 1990) and others (Widen et al., 1992) of specific ligands for the vesicular acetylcholine transporter. $\left[{ }^{11} \mathrm{C}\right] \mathrm{Tetrabenazine}$ and related labeled benzoisoquinolines (DaSilva et al., 1992) show good potential for PET imaging of monoaminergic nerve terminals; development of analogous agents for single photon emission computed tomography (SPECT) is being pursued by others (Kung et al., 1992). In vivo imaging with such agents provides a new approach to the study of monoaminergic nerve terminals.

\section{ACKNOWLEDGMENTS}

This work was supported in part by grants from the Alcohol, Drug, and Mental Health Administration (MH47611), National Institutes of Health (NS15655), and Department of Energy (DE-FG02-88ER60639), and a fellowship from the Fonds de Recherche en Sante du Quebec (to J.N.D.). The authors thank Phil Sherman, Teresa Pisani, John Caraher, and Dr. Robert Koeppe for assistance with the animal studies, and Drs. David E. Kuhl, Kirk A. Frey, and Donald M. Wieland for many helpful discussions.

\section{REFERENCES}

Aquilonius, S.M., Bergstrom, K., Eckernas, S.A., Hartvig, P., Leenders, K.L., Lundquist, H., Antoni, G., Gee, A., Rimland, A., Uhlin, J. and Langstrom, B. (1987) In vivo evaluation of striatal dopamine reuptake sites using ${ }^{11} \mathrm{C}$-nomifensine and positron emission tomography. Acta Neurol. Scand., 76:283-287.

Bankewicz, K.S., Oldfield, E.H., Chieuh, C.C., Doppman, J.L., Jacobowitz, D.M., and Kopin, I.J. (1986) Hemiparkinsonism in monkeys after unilateral internal carotid artery infusion of 1-methyl-4-phenyl-1,2,3,6-tetrahydropyridine (MPTP). Life Sci., 39:7-16.

Buu, N.T. (1989) Modification of vesicular dopamine and norepinephrine by monoamine oxidase inhibitors. Biochem. Pharm., 38:16851692 .

DaSilva, J.N., and Kilbourn, M.R. (1992) In vivo binding of $\left[{ }^{11} \mathrm{C}\right]$ tetrabenazine to vesicular monoamine transporters in mouse brain. Life Sci., 51:593-600.

DaSilva, J.N., Kilbourn, M.R., Mangner, T.J., and Toorongian, S.A (1993) Synthesis of $\left[{ }^{11} \mathrm{C}\right]$ tetrabenazine and a $\left[{ }^{11} \mathrm{C}\right]$ methoxy derivative of $\alpha$-dihydrotetrabenazine for PET imaging of monoaminergic nerve terminals. J. Labeled Compds. Radiopharm., 32:257-259.

Fowler, J.S., Volkow, N.D., Wolf, A.P., Dewey, S.L., Schlyer, D.J. MacGregor, R.R., Hitzemann, R., Logan, J., Bendreim, B., Gatley, S.J., and Christman, D. (1989) Mapping cocaine binding sites in human and baboon brain in vivo. Symapse, 4:371-377.

Giros, B., Mestikawy, S.E., Godinot, N., Zheng, K., Han, H., YangFeng, T., and Caron, M.G. (1992) Cloning, pharmacological characterization, and chromosome assignment of the human dopamine transporter. Mol. Pharmacol., 42:383-390.

Ikegami, H., and Prasad, C. (1990) Neuropeptide-dopamine interactions. V. Cyclo(His-Pro) regulation of striatal dopamine transporter complex. Peptides, 11:145-148.

Innis, R., Baldwin, R., Sybirska, E., Zea, Y., Laruelle, M., Al-Tikriti,
M., Charney, D., Zoghbi, S., Wisniewski, G., Hoffer, P., Wang, S., Milius, R., and Neumeyer, J. (1991) Single photon emission computed tomography of monoamine reuptake sites in primate brain with [ [ $\left.{ }^{23} I\right]$ CIT. Eur. J. Pharm., 200:369-370.

Jung, Y.-W., Van Dort, M.E., Gildersleeve, D.L., and Wieland, D.M. (1990) A radiotracer for mapping cholinergic neurons of the brain. J. Med. Chem., 33:2065-2068.

Kilbourn, M.R., Sherman, P.S., and Pisani, T. (1992) Repeated reserpine administration reduces in vivo $\left[{ }^{18} \mathrm{~F}\right] \mathrm{GBR} 13119$ binding to the dopamine uptake site, Eur. J. Pharm., 216:109-112.

Kilbourn, M.R., Carey, J.E., Koeppe, R.A., Haka, M.S., Hutchins, G.D., Sherman, P.S., and Kuhl, D.E. (1989) Biodistribution, dosimetry, metabolism and monkey PET studies of ${ }^{18}$ F]GBR 13119. Imaging the dopamine uptake system in vivo. Nucl. Med. Biol., 16:569-576.

Kilbourn, M.R., Jung, Y.-W., Haka, M.S., Gildersleeve, D.L., Kuhl, D.E., and Wieland, D.M. (1990) Mouse brain distribution of a carbon-11 labeled vesamicol derivative: presynaptic marker of cholinergic neurons. Life Sci., 47:1955-1963.

Koeppe, R.A., Kilbourn, M.R., Frey, K.A., Penney, J.B., Haka, M.S., and Kuhl, D.E. (1990) Imaging and kinetic modeling of [F-18]GBR 12909, a dopamine uptake inhibitor. J. Nucl. Med., 31:720.

Kung, M.P., Canney, D., Guo, Y.Z., Billings, J., and Kung, H.F. (1992) Iodinated derivatives of tetrabenazine for mapping monoamine storage sites. Soc. Neurosci. Abst, 18:475.

Lee, C.-M., Javitch, J.A., and Snyder, S.A. (1983) Recognition sites for norepinephrine uptake: regulation by neurotransmitter. Science, 220:626-629

Leenders, K.L., Aquilonius, S.-M, Bergstrom, K., Bjurling, P., Crossman, A.R., Eckernas, S.-A., Gee, A.G., Hartvig, P., Lundqvist, H., Langstrom, B., Rimland, A., and Tedroff, J. (1989) Unilateral MPTP lesion in a rhesus monkey: Effects on the striatal dopaminergic system measured in vivo with PET using various novel tracers. Brain Res., 445:61-67.

Liu, Y., Peter, D., Roghani, A., Schuldiner, S., Prive, G.G., Eisenberg, D., Brecha, N., and Edwards, R.H. (1992) A cDNA that suppresses $\mathrm{MPP}+$ toxicity encodes a vesicular amine transporter. Cell, 70:539551

Masuo, Y., Pelaprat, D., Scherman, D., and Rostene, W. (1990) $\left.\right|^{3} \mathrm{H} \mid \mathrm{Di}$ hydrotetrabenazine, a new marker for the visualization of dopaminergic denervation in the rat striatum. Neurosci. Lett., 114:45-50.

Scheffel, U., Steinert, C.L., Kuhar, M.J., and Neumeyer, J.L. (1991) Effect of endogenous dopamine on ${ }^{3} \mathrm{H}-$ WIN-35,428 binding to dopamine uptake sites. J. Nucl. Med., 32:1069.

Scherman, D., Boschi, G., Rips, R., and Henry, J.-P. (1986) The regionalization of $\left[{ }^{3} \mathbf{H}\right]$ dihydrotetrabenazine binding sites in the mouse brain and its relationship to the distribution of monoamines and their metabolites. Brain Res., 370:176-181.

Scherman, D., Desnos, C., Darchen, F., Pollak, P., Javoy-Agid, F., and Agid, Y. (1989) Striatal dopamine deficiency in Parkinson's disease: role of aging. Ann. Neurol., 26:551-557.

Sharpe, L.G., Pilotte, N.S., Mitchell, W.M., and DeSouza, E.B. (1991) Withdrawal of repeated cocaine decreases autoradiographic $\left[{ }^{3} \mathrm{H}\right]$ mazindol-labelling of dopamine transporter in rat nucleus accumbens. Eur. J. Pharmacol., 203:141-144.

Shaya E.K., Scheffel, U., Dannals, R.F., Ricuarte, G.A., Carroll, F.I., Wagner, H.N. Jr., Kuhar, M.J., and Wong, D.F. (1992) In vivo imaging of dopamine reuptake sites in the primate brain using single photon emission computed tomography (SPECT) and iodine-123 labeled RTI-55. Synapse, 10:169-172.

Slotkin, T.A., and Bareis, D.L. (1980) Uptake of catecholamines by storage vesicles. Pharmacology, 21:109-122.

Uhl, G.R. (1992) Neurotransmitter transporters (plus): A promising new gene family. Trends Neurosci., 15:265-268.

Widen, L., Eriksson, L., Ingvar, M., Parsons, S.M., Rogers, G.A., and Stone-Elander, S. (1992) Positron emission tomographic studies of central cholinergic nerve terminals. Neurosci. Lett., 136:1-4.

Wiener, H.L., Hashim, A., Lajtha, A., and Sershen, H. (1989) Chronic L-deprenyl-induced up-regulation of the dopamine uptake carrier. Eur. J. Pharmacol, 163:191-194.

Wong, D.F., Shaya, E.K., Yung, B., Scheffel, U., Dannals, R.F., Ricuarte, G.A., Chen, C., Neumeyer, J.L., Wagner, H.N., Jr., and Kuhar, M.J. (1992) C-11 WIN 35,428 imaging of the dopamine transporter site in living human brain. J. Nucl. Med., 33:964.

Zigmond, R.E. (1985) Biochemical consequences of synaptic stimulation: The regulation of tyrosine hydroxylase activity by multiple transmitters. Trends Neurosci., 8:63-70. 